\title{
Association between frontal sinus development and persistent metopic suture
}

\author{
S. Bilgin'1, U.H. Kantarcl2 , M. Duymus², C.H. Yildirim³, B. Ercakmak4 , G. Orman², \\ C. Gunenc Beser', M. Kaya ${ }^{3}$, M. Gok², A. Akbasak ${ }^{3}$ \\ ${ }^{1}$ Department of Anatomy, Kafkas University Faculty of Medicine, Kars, Turkey \\ ${ }^{2}$ Department of Radiology, Kafkas University Faculty of Medicine, Kars, Turkey \\ ${ }^{3}$ Department of Neurosurgery, Kafkas University Faculty of Medicine, Kars, Turkey \\ ${ }^{4}$ Department of Anatomy, Hacettepe University Faculty of Medicine, Ankara, Turkey
}

[Received 10 June 2013; Accepted 14 July 2013]

Background: Frontal sinuses are 2 irregular cavities, placed between 2 lamina of frontal bone. Expansion continues during childhood and reaches full size after puberty. Persistent metopic suture is one of the factors that are related to abnormal frontal sinus development. In this study, we want to discuss about the coexistence of persistent metopic suture and abnormal frontal sinus development using radiological techniques.

Materials and methods: In this retrospectively planned study, images of 631 patients were examined, 217 (34.4\%) of them were men and 414 (65.6\%) of them were women. Brain computed tomography and magnetic resonance images were retrieved from the electronic archive for analysis.

Results: In this study, frontal sinus development is categorised as right side atrophy, left side atrophy, bilateral atrophy and bilaterally developed sinuses. The presence of metopic suture was accepted as persistent metopic suture. Frontal sinus atrophy was found in $22.7 \%$ and persistent metopic sutures were found in $9.7 \%$ of overall.

Conclusions: In this study, no significant results were detected that were related to the frontal sinus agenesis or dismorphism associated with persistent metopic suture. We conclude that, although publications propounding metopism that leads to abnormal frontal sinus development are present in the literature, no reasonable explanation has been mentioned in these articles; and we believe that these findings are all incidental. (Folia Morphol 2013; 72, 4: 306-310)

Key words: frontal sinus, atrophy, metopic suture, computed tomography imaging, magnetic resonance imaging

\section{INTRODUCTION}

Frontal sinuses are 2 irregular cavities placed between 2 lamina of frontal bone [29]. They are the last paranasal sinuses to develop [23]. They are rudimentary at birth and can be radiologically visible by 6 years. Expansion continues during childhood and reaches the full size after puberty. Size and shape of the frontal sinuses differ by age and sex. Also
2 sinuses of the same person differ in shape and size because of the septum deviated from the median plane [29]. Several septa may be seen besides the median septum $[9,10]$. As the radiological morphology is individualised, shape of the sinuses can be valuable in identification of a person [29].

Many factors related to abnormal frontal sinus development are mentioned in literature, such as gender 
or ethnic groups $[6,8]$. Persistent metopic suture is one of these factors [7, 20, 28]. Metopic suture is a kind of dentate suture $[4,12,13]$. It lies between 2 halves of the frontal bone and extends from nasion to bregma $[1,19,28]$. This suture normally closes between first and second year of life, however fusion can be completed until the age of 7 [27]. If the metopic suture persists after the $7^{\text {th }}$ year of life, it is known as 'metopism' [28], and it is said that frontal sinus development may be affected by this entity $[20,21]$. Metopic suture persistence can be visualised particularly or completely $[12,20]$. Some authors think that abnormal frontal sinus development can be grounded on particular or complete persistent metopic suture that extends to the inferior part of the frontal bone $[20,28]$. Frontal sinuses of a person with persistent metopic suture develop separately on either side of the suture and this entity can be used to differentiate persistent metopic suture from fracture [29].

\section{MATERIALS AND METHODS}

In this retrospectively planned study, the images that were taken from the patients who applied to our center between September 2011 and April 2012 were analysed. We identified brain computed tomography (CT) and brain magnetic resonance (MR) images that could be retrieved from the electronic archive for the analysis.

All CT scans were obtained with 64-slice spiral scanner (Toshiba Aqulion). As a standard, slice thickness and interval were set at 5 and $3 \mathrm{~mm}$. Scanning parameters included $550 \mathrm{~mA}, 135 \mathrm{kV}$ and tube rotation time of $1.5 \mathrm{~s}$. When the imaging was performed, the head was in neutral position.

MR scans were performed with 1.5 tesla MR scanner (Siemens, Essenza). T1 and T2 axial, coronal and sagittal images were examined.

Then both MR and CT images were forwarded into the viewer program (Aquarius intuition viewer version 4.4.6).

The study parameters were age, sex, frontal sinus development, and metopic suture presence. Frontal sinus development was noted as right side atrophy, left side atrophy, bilateral atrophy, and bilaterally developed. Unfusion of metopic suture was accepted as persistent metopic suture.

\section{Statistical analysis}

SPSS (Statistical Package for Social Sciences) version 17 was used to make statistical analyses. Independent Sample T test was used to detect the

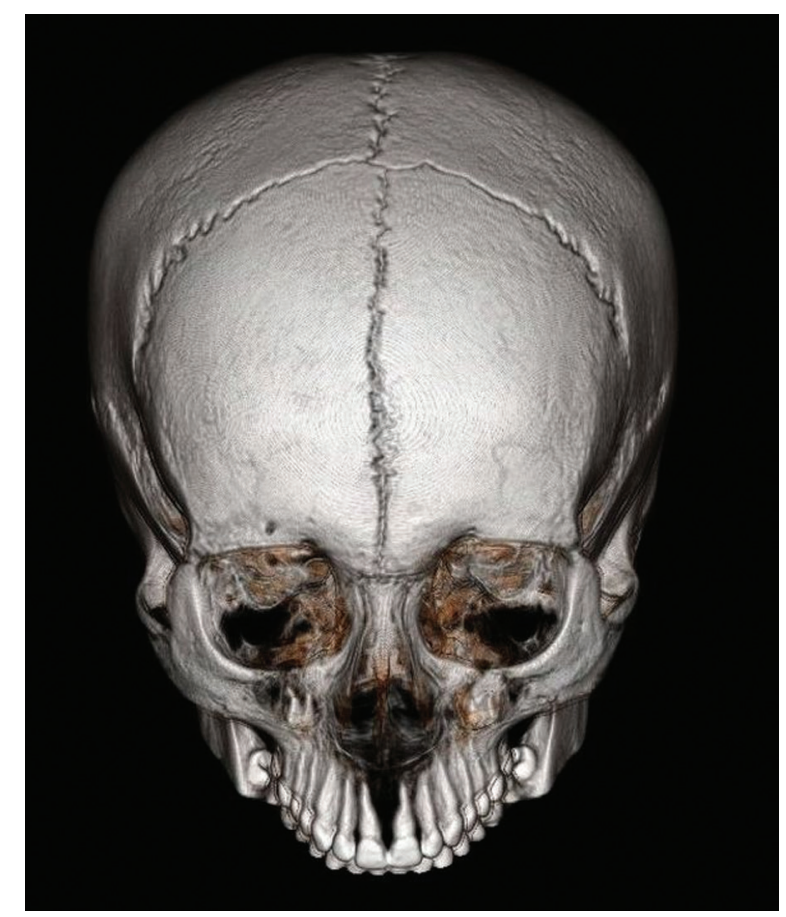

Figure 1. Persistent metopic suture is seen as vertical line at the coronal midline of cranium in 3-dimensional volume rendered computed tomography image of cranium in bone window.

correlation between metopic suture and frontal sinus atrophy. A p value of less than 0.5 was indicative of statistical significance.

\section{RESULTS}

219 cranial CT (34.7\%) and 412 cranial MR (65.3\%) images retrieved from the electronic archive were identified. 217 (34.4\%) of the study patients were men, 414 (65.6\%) were women. The mean age of the patients was $48.37 \pm$ SD (between 30-93). Frontal sinus development and the presence of metopic sutures were investigated.

In this study, frontal sinus development is categorised as right-side atrophy, left-side atrophy, bilateral atrophy and bilaterally developed sinuses. The presence of metopic suture was accepted as persistent metopic suture.

Frontal sinus atrophy was found in $22.7 \%$ of overall, including $9.4 \%$ right sided, $2.9 \%$ left sided and $10.5 \%$ bilaterally.

Persistent metopic sutures were found in $9.7 \%$ of overall (Fig. 1).

Frontal sinus atrophy was found in $24.6 \%$ of the patients with persistent metopic suture (Table 1). Out of the patients with persistent metopic suture, frontal sinus 
atrophy was detected as $46.7 \%$ right-sided (Fig. 2), $13.3 \%$ left-sided and $40 \%$ bilaterally. Bilateral development was found in $75.4 \%$ of the patients with persistent metopic suture (Table 2).

Frontal sinus atrophy was found in $22.5 \%$ of the patients without persistent metopic suture (Table 1). Out of the patients without persistent metopic suture, frontal sinus atrophy was detected as $40.6 \%$ right-sided, $12,5 \%$ left-sided and $46.9 \%$ bilaterally (Table 2 ).

Bilateral development was found in $77.5 \%$ of the patients without persistent metopic suture.

Table 1. The correlation between persistent metopic suture and frontal sinus atrophy

\begin{tabular}{lcccc}
\hline & & \multicolumn{2}{c}{ Atrophy } & Total \\
\cline { 3 - 4 } & & + & - & \\
\hline Metopic suture & + & $15(24.6 \%)$ & $46(75.4 \%)$ & 61 \\
& - & $128(22.5 \%)$ & $442(77.5 \%)$ & 570 \\
Total & & 143 & 488 & 631 \\
\hline
\end{tabular}

No correlation between persistent metopic suture and frontal sinus development was detected $(p>0.05)$ (Table 3).

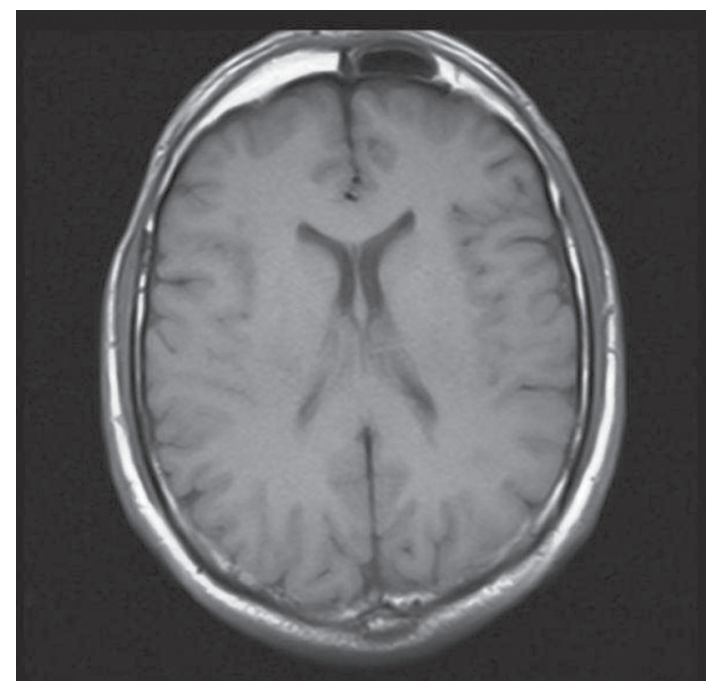

Figure 2. The agenetic right compartment of the frontal sinus is seen in the axial image of cranium in magnetic resonance images.

Table 2. Side distributions of the patients with metopic suture and frontal sinus atrophy together

\begin{tabular}{|c|c|c|c|c|c|c|c|}
\hline \multirow{2}{*}{$\begin{array}{l}\text { Metopic suture } \\
\text { Exist }\end{array}$} & \multicolumn{3}{|c|}{ Atrophy } & \multirow{2}{*}{$\begin{array}{l}\text { Frequency } \\
46\end{array}$} & \multirow{2}{*}{$\begin{array}{c}\text { Per cent } \\
100,0\end{array}$} & \multirow[t]{2}{*}{ Valid per cent } & \multirow[t]{2}{*}{ Cumulative per cen } \\
\hline & Absent & Missing & System & & & & \\
\hline & Exist & Valid & Right & 7 & 46.7 & 46.7 & 46.7 \\
\hline & & & Left & 2 & 13.3 & 13.3 & 60.0 \\
\hline & & & Bilateral & 6 & 40.0 & 40.0 & 100.0 \\
\hline & & & Total & 15 & 100.0 & 100.0 & \\
\hline \multirow[t]{5}{*}{ Absent } & Absent & Missing & System & 442 & 100.0 & & \\
\hline & Exist & Valid & Right & 52 & 40.6 & 40.6 & 40.6 \\
\hline & & & Left & 16 & 12.5 & 12.5 & 53.1 \\
\hline & & & Bilateral & 60 & 46.9 & 46.9 & 100.0 \\
\hline & & & Total & 128 & 100.0 & 100.0 & \\
\hline
\end{tabular}

Table 3. $P$ value of the $\chi^{2}$ tests is 0.828 and showed no significant result related to frontal sinus agenesis or dismorphism associated with persistent metopic suture

\begin{tabular}{lccccc}
\hline & Value & df & Asymp. Sig. (2-sided) & Exact Sig. (2-sided) & Exact Sig. (1-sided) \\
\hline Pearson $\chi^{2}$ & $0.143^{\mathrm{a}}$ & 1 & 0.705 & & \\
Continuity correction & 0.047 & 1 & 0.828 & & \\
Likelihood ratio & 0.141 & 1 & 0.708 & 0.748 & \\
Fisher's exact test & & & & & \\
Linear-by-linear association & 0.143 & 1 & 0.705 & \\
No. of valid cases & 631 & & & & \\
\hline
\end{tabular}

${ }^{a} 0$ cells $(0 \%)$ have expected count less than 5 . The minimum expected count is 13.82 ; ${ }^{\text {CC}}$ omputed only for a $2 \times 2$ table 


\section{DISCUSSION}

There are 2 types of cranial bones in the head; those formed through the ossification of a cartilaginous intermediate are known as 'endochondral bones', and those formed through the direct ossification in the mesenchyme are known as 'membrane bones' or 'dermal bones'.

The cranium is composed of 3 layers. The endochranium, which encloses the brain and helps to form the sensory capsules that support and protect the olfactory organs, eyes, and inner ears; an external protective layer of membrane (dermal) bones; and the viscerocranium that supports the jaws. The cranial bones can be divided into the neurocranium and viscerocranium. The neurocranium encompasses the bones surrounding and protecting the brain and sensory organs - the endochondral bones of the base of cranium and sensory organs, and the dermal bones of the skull vault. The viscerocranium encompasses the bones of face and pharyngeal arches [5, 26].

In humans, the chondrocranium is the portion of the skull formed by endochondral ossification. It is developed from 3 pairs of precursors. These cartilages contribute to the cranial base and, together with cartilaginous capsules that develop around the otic and nasal pits help to protect the brain and sensory organs. This portion of the skull is the first to form in the embryo. The flat bones of the cranial vault calvaria are consisted of membrane-bone armor that covers the skull.

The bones of the cranial vault do not complete their growth during foetal life. The soft, fibrous sutures allow them to continue growing throughout infancy and childhood. During foetal life, the so-called sutural space - metopic suture, separates 2 frontal bones; it consists of fibrous tissue and mesenchymal cells responsible for the growth of the frontal bones [18]. The metopic suture closes normally before the second year of life, while the closure of the rest of the calvarial sutures occurs between $26^{\text {th }}$ and $36^{\text {th }}$ month.

The frontal sinuses do not form until the $5^{\text {th }}$ or $6^{\text {th }}$ postnatal year and they expand throughout adolescence. Each frontal sinus actually consists of 2 independent spaces that develop from different sources. One is developed from the expansion of the ethmoid sinus into the frontal bone, and other is developed from an independent invagination of the middle meatus of the nasal passage; they never coalesce [25]. As the growth of the inner table ceases at the age of 6-7 when the frontal lobes have reached their major development, evolution of the frontal sinuses begin according to the continuous growth of the outer table in response of the stimulus of the growing nasomaxillary facial complex [27].

Many authors have performed descriptive or experimental studies regarding cranial sutures and their evolution either in man $[9,16,19,23]$, or in animals [3, 18, 23]. In these studies, histological and microradiographic aspect of the metopic suture was well defined before, during, and after its closure. Although there is abundant data about the closure of the metopic suture, little or no information is encountered on persistent form of it. Neither embryologic, nor histological information can be obtained from the investigations performed until today regarding the persistence of metopic suture and its relation to frontal sinus agenesis. Pneumatisation of the frontal sinuses occurs after the $5^{\text {th }}$ or $6^{\text {th }}$ postnatal year, while frontal bones and metopic suture are developing in early foetal life; thus there should be no embryologic, and temporal relation concerning the development of these 2 anatomic structures. Adverse effect of a persistent metopic suture on the development of the frontal sinuses seems unlikely. Conversely, it is well known that premature closing of the cranial sutures in craniosynostosis results in atretic frontal sinuses due to increased intracranial pressure hindering pneumatisation of the sinuses. In a study conducted by Locher et al. [17], frontal sinus pneumatisation following bilateral fronto-orbital advancement was seen in 24 of 33 patients with craniosynostosis [14]. On the other hand, individuals with persistent metopic suture are otherwise neurologically and physically normal.

There are publications suggesting the persistent metopic suture was associated with the absence of frontal sinus; however, none of them are based on a scientific work or explanation $[2,6]$. Since the plain $X$-ray exams are not as sensitive as the CT and MRI studies, correct results from the investigations related to skull anatomy can be obtained from the CT and MRI scans, or from the autopsy material and cadavers only. Results acquired from the material consisting of $X$-rays are prone to misinterpretation arising either from the erroneous evaluation of the radiograms or their insufficient resolution. Baaten et al. [2] declared that the absence of frontal sinus was found in 7 of the 8 cases of metopism in a study they carried out on 968 skull X-rays. In that study they also admit that some irrelevant results to the literature they obtained could be due to the use of X-rays rather than cadavers. 
Moreover, in many studies the absence of frontal sinuses was found at rates changing from $5 \%$ to $27.9 \%$ regardless of persistence of the metopic suture [12, 15, 22].

Normal skull anatomy such as vascular grooves, developmental fissures, and straighter-appearing suture lines of the lamina interna can mimic, and be mistaken for fractures. Persistent metopic suture is one of these markings and may cause misdiagnosis as a linear fracture. Misdiagnosed metopic suture may also cause therapeutic mistakes and unnecessary interventions. Neurosurgeons desire to be informed about all anatomical configurations on the skull before a cranial surgery. A persistent metopic suture should be revealed prior to a frontal craniotomy. It should be kept in mind that routine radiographs of the skull can be more sensitive than CT in the detection of linear fractures and other linear formations. Therefore, meticulous radiographic examinations, including 3-dimensional CT, should be performed for the correct diagnosis. On the other hand, prominent suture areas can also be noted in hydrocephalus, cerebritis, brain neoplasms, metastasis, leukaemia, lymphoma, and other causes of increased intracranial pressure [11, 24, 30].

No data were found correlating the persistence metopic suture to the frontal sinusitis and other pathologies of the frontal sinuses in the literature.

\section{CONCLUSIONS}

In the present study, no significant result was detected relating to frontal sinus agenesis or dismorphism that is associated with persistent metopic suture. We conclude that, although publications propounding metopism that leads to abnormal frontal sinus development are present in the literature, no reasonable explanation has been mentioned in these articles; and we believe that these findings are all incidental.

\section{REFERENCES}

1. Ajmani ML, Mittal RK, Jain SP (1983) Incidence of the metopic suture in adult Nigerian skulls. J Anat, 137: 177-183.

2. Baaten PJJ, Haddad M, Abi-Nader K (2003) Incidence of metopism in the Lebanese population. Clin Anat, 16: 148-152.

3. Babler WJ, Persing JA, Nagorsky MJ (1987) Restricted growth at the frontonasal suture: alterations in craniofacial growth in rabbits. Am J Anat, 178: 90-98.

4. Bademci G, Kendi T, Agalar F (2007) Persistent metopic suture can mimic the skull fractures in emergency setting? Neurocirugia, 18: 238-240.

5. Bryce TH (1915) Osteology and arthrology. In: Quain's elements of anatomy. $11^{\text {th }}$ Ed. Vol. 4. Longmans Green London, p. 177.
6. Cakur B, Sumbullu MA, Bayindir Durna N (2011) Aplasia and agenesis of the frontal sinus in Turkish individuals: a retrospective study using dental volumetric tomography. Int J Med Sci, 8: 278-282.

7. Das S, Suri R, Kapur V (2005) Anatomical observations on os inca and associated cranial deformities. Folia Morphol, 64: 118-121.

8. Del Sol M, Binvignat O, Bolini PD, Prates JC (1989) Metopism in Brazilians. Rev Paul Med, 107: 105-107.

9. Dhem A, Dambrain R, Thauvoy CH (1983) Contribution to the histological and microradiographical study of the craniostenosis. Acta Neurochir, 69: 259-272.

10. Dwivedi AND, Singh KK (2010) CT of the paranasal sinuses: normal anatomy, variants and pathology. J Optoelectronics Biomedical Materials, 4: 281-289.

11. Eisenberg RL (1994) Skull and spine imaging: an atlas of differential diagnosis. Raven Press, New York.

12. Gulisano M, Pacini P, Orlandini GE (1978) Frontal sinus dimentions in reletion to the cranial index. Boll Soc Ital Bio Sper, 54: 66-69.

13. Hussain Saheb S, Mavishetter GF, Thomas ST, Prasanna LC (2010) Incidence of metopic suture in adult South Indian skulls. J Biomed Sci and Res, 2: 223-226.

14. Jane JA, Edgerton MT, Futrell JW (1978) Immediate correction of sagittal synostosis. J Neurosurg, 49: 705-710.

15. Krogman WM (1962) The human skeleton in forensic medicine. Spring field, Thomas.

16. Latham RA, Burston WR (1966) The postnatal pattern of growth at the sutures of the human skull. Dental Practicioner, 17: 61-679.

17. Locher MC, Sailer HF, Haers P (1998) Development of frontal sinus following bilateral fronto-orbital osteotomies. J Cran-Max Surg, 26: 129-135.

18. Manzaranes MC, Goret-Nicaise M, Dhem A (2002) Metopic sutural closure in human skull. J Anat, 161: 203-215.

19. Moss ML (1958) Fusion of the frontal suture in the rat. Am J Anat, 102: 141-165.

20. Murlimanju BV, Prabhu LV, Pai MM, Goveas AA, Dhananjaya KVN, Somesh MS (2011) Median frontal suturesincidence, morphology and their surgical, radiological importance. Turkish Neurosurgery, 21: 489-493.

21. Newton T, Potts GD (1971) Radiology of the skull and brain. Vol. 1. The Skull The C. V. Mosby Company, Saint Louis.

22. Ponde JM, Andrade RN, Via JM (2008) Anatomical variations of the frontal sinus. Int J Morphol, 26: 803-808 .

23. Pritchard JJ, Scott JH, Girgis FG (1956) The structure and development of cranial and facial sutures. J Anat, 90: 73-86.

24. Reeder MM, Bradley WG (1993) Reeder and Felson'gamuts in radiology. 3rd Ed. Springer-Verlag, New York.

25. Schoenwolf GC, Bleyl SB, Brauer PR, Francis-West PH (2009) Development of the pharyngeal apparatus and face. In: Schoenwolf GC ed. Larsen's human embryology. Churchill Livingstone Elsevier, Philadelphia, pp. 543-584.

26. Scuderi AJ, Harnsberger GR, Boyer RS (1993) Pneumatization of the paranasal sinuses: Normal features of importance to the accurate interpretation of CT scans and MR images. AJR, 160: 1101-1104.

27. Shapiro R, Shorr SA (1980) A consideration of systemic factors that influence frontal sinus pneumatization. Invest Radiol, 15: 191-202.

28. Skrzat J, Walocha J, Zawilinski J (2004) A note on the morphology of the metopic suture in the human skull. Folia Morphol, 63: 481-484.

29. Standring S (2008) Gray's anatomy. $40^{\text {th }}$ Ed. Churghill Livingstone Elseiver, Spain.

30. Swischuk L (1984) Differential diagnosis in pediatric radiology. Williams \& Wilkins, Baltimore. 